\title{
ANTI-INFLAMMATORY TRITERPENOIDS FROM MYSTERIOUS MUSHROOM GANODERMA LUCIDUM AND THEIR POTENTIAL POSSIBILITY IN MODERN MEDICINE
}

\author{
Jiři Patočka \\ Purkyně Military Medical Academy, Hradec Králové: Department of Toxicology \\ Summary: Ganoderma lucidum, a mushroom long used in the East for a broad range of disorders, contains numerous \\ pharmacologically active compounds. Very important of them are highly oxygenated anti-inflammatory triterpenes, which \\ are the aim of this mini-review.
}

Key words: Ganoderma lucidum; Mushroom; Anti-inflammatory triterpenoids; Alzheiemer's disease

\section{Introduction}

A mushroom Ganoderma lucidum was acclaimed as a divine herb that could bestow longevity. It was also deemed an elixir of life that could augment good health and well-being (13). This is probably the case when certain mushrooms were treated as objects of worship or as objects of mysteries describing them as celestial herbs possessing panaceal properties (6). G. lucidum, also called Reishi or Ling-zhi, is the most important elixir in the Orient and one of the most well-known medicinal fungus in the Chinese pharmacopoeia. It has been used in China for over thousands of years as a miraculous remedy to treat more than 20 different illnesses which include migraine and headache, hypertension, arthritis, asthma, bronchitis, gastritis, haemorrhoids, anorexia, hypercholesterolaemia, nephritis, dysmenorrhoea, hepatitis, constipation, lupus erythematosis, leukopenia, traumatic wounds, infammation, various ulcers, cardiovascular problems and cancer including leukemia (4). Immunosuppressive activity of this mushroom has been also estimated (9). For centuries, Ganoderma lucidum has been used in Oriental medicine for the treatment of chronic bronchitis as anti-allergic remedy $(24,25)$. In some ancient reports Ling-Zhi was praised for its effect of increasing memory and preventing forgetfulness in old age as for instance in the book Shen Nong Ben Cao Jing as early as in 456-536 AD. Although some of the therapeutic claims of this medicinal fungus may be exaggerated, recent scientific reports from many sources show that some of the therapeutic properties of G. lucidum can now be substantiated. Nowadays, modern research has revealed its active ingredients, which may be important not only for elucidating the mechanism of action of these molecules, but also for future analog drug development.

\section{Pharmacologically Active Components in Ganoderma lucidum}

Variety pharmacologically active compounds has been identified in Ganoderma lucidum. There are mainly steroides (ergosterol, ganodesteron, 24-methylcholesta-7,22-dien-3, or -6-ol), nucleosides and nucleotides (adenosin, guanosin, 5'-GMP, 5'-XMP, and 5'-deoxy-5'-methylsulphinyl adenosine which is a strong platelet aggregation inhibitor), glycanes and proteoglycanes (polysaccharideprotein complexes Ganoderan B and C) with hypoglycemic activity, peptidoglycan (MW $100 \mathrm{kDa}$ ) with blood pressure stabilizing effect, lectins, and cytotoxic polysaccharides (various hetero-(-8-Dglycans) and triterpenoids (ganoderic acids) $(5,17)$. Different vitamins, oils, coumarine-glycosids, and inorganic ions as $\mathrm{Mg}, \mathrm{Zn}, \mathrm{Ca}, \mathrm{Cu}, \mathrm{Fe}$, and $\mathrm{Ge}$ were also identified in this mushroom. Germanium in the form of organic compound, bis- $\beta$-karboxyethyl-germanium-sesquioxide, now called GE-132, was found in G. lucidum in high concentration. Medical research studies have indicated that GE-132 can induce gamma-interferon and activate macrophages and natural killer cells. Other results were reported showing beneficial effects on malignancies and rheumatoid arthritis (1).

\section{Anti-inflammatory Compounds from Ganoderma lucidum}

Stavinoha et al. (22) found G. lucidum to be a potent anti-inflammatory agent. The water and/or methanolic extract of the fruiting body was active orally against both carrageenan induced inflammation and croton oil induced inflammation. Ammelioration of the pain and inflammation associated with arthritis has historically been attributed 
to preparations of G. lucidum (12). Active compounds were isolated and identified as highly oxygenated acidic triterpenoids (11) by HPLC chromatography (23).

Chemical structures of the most important triterpenoids isolated from $G$. lucidum are summarized in Tables 1 and 2. Anti-inflammatory activity of many ganoderma triterpenoids is comparable with the effect of some nonsteroidal anti-inflammatory compounds such as indomethacine (10). Stavinoha et al. (22) found that active compounds isolated from $\mathrm{G}$. lucidum is equivalent in anti-inflammatory activity to hydrocortisone. It does not show the typical side effects of steroids such as thymic involution nor appears to cause gastropathy which is the major side effect of the nonsteroidal anti-inflammatory drugs such as aspirin.

Tab. 1: Structures of compounds isolated from the fruiting bodies of Ganoderma lucidum.

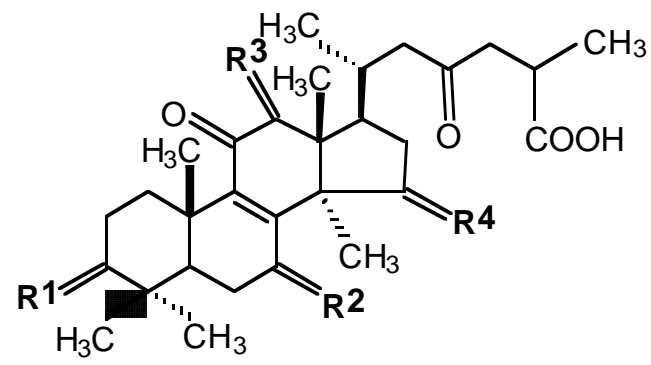

\begin{tabular}{|l|c|c|c|c|}
\hline Compound & $\mathbf{R}^{\mathbf{1}}$ & $\mathbf{R}^{\mathbf{2}}$ & $\mathbf{R}^{\mathbf{3}}$ & $\mathbf{R}^{\mathbf{4}}$ \\
\hline Ganoderic acid A & $\mathrm{O}$ & $\mathrm{OH}, \mathrm{H}$ & $\mathrm{H}_{2}$ & $\mathrm{OH}, \mathrm{H}$ \\
\hline Ganoderic acid B & $\mathrm{OH}, \mathrm{H}$ & $\mathrm{OH}, \mathrm{H}$ & $\mathrm{H}_{2}$ & $\mathrm{O}$ \\
\hline Ganoderic acid H & $\mathrm{OH}, \mathrm{H}$ & $\mathrm{O}$ & $\mathrm{OAc}, \mathrm{H}$ & $\mathrm{O}$ \\
\hline Ganoderic acid CI & $\mathrm{O}$ & $\mathrm{OH}, \mathrm{H}$ & $\mathrm{H}_{2}$ & $\mathrm{O}$ \\
\hline Ganoderic acid G & $\mathrm{OH}, \mathrm{H}$ & $\mathrm{OH}, \mathrm{H}$ & $\mathrm{OH}, \mathrm{H}$ & $\mathrm{O}$ \\
\hline Ganoderic acid K & $\mathrm{OH}, \mathrm{H}$ & $\mathrm{O}$ & $\mathrm{H}_{2}$ & $\mathrm{OH}, \mathrm{H}$ \\
\hline
\end{tabular}

Tab. 2: Structures of compounds isolated from the fruiting bodies of Ganoderma lucidum.

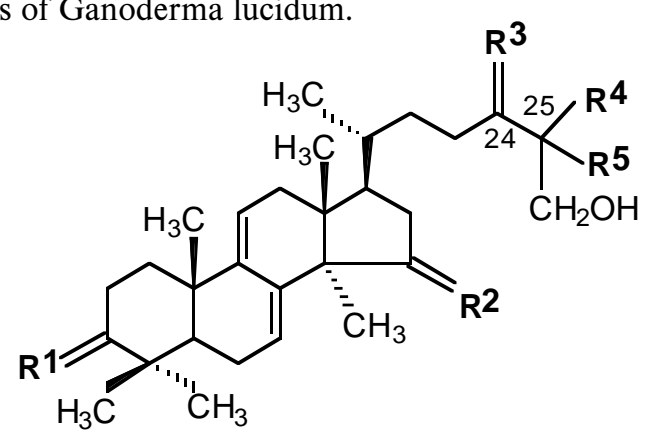

\begin{tabular}{|l|c|c|c|c|c|}
\hline Compound & $\mathbf{R}^{\mathbf{1}}$ & $\mathbf{R}^{\mathbf{2}}$ & $\mathbf{R}^{\mathbf{3}}$ & $\mathbf{R}^{\mathbf{4}}$ & $\mathbf{R}^{\mathbf{5}}$ \\
\hline Ganoderiol A & $\mathrm{OH}, \mathrm{H}$ & $\mathrm{H}_{2}$ & $\mathrm{OH}, \mathrm{H}$ & $\mathrm{OH}$ & $\mathrm{CH}_{3}$ \\
\hline Ganoderiol B & $\mathrm{O}$ & $\mathrm{OH}, \mathrm{H}$ & $\Delta^{24(25)}$ & & $\mathrm{CH}_{2} \mathrm{OH}$ \\
\hline Ganoderiol F & $\mathrm{O}$ & $\mathrm{H}_{2}$ & $\Delta^{24(25)}$ & & $\mathrm{CH}_{2} \mathrm{OH}$ \\
\hline Ganodermanontriol & $\mathrm{O}$ & $\mathrm{H}_{2}$ & $\mathrm{OH}, \mathrm{H}$ & $\mathrm{OH}$ & $\mathrm{CH}_{3}$ \\
\hline
\end{tabular}

\section{Anti-inflammatory Compounds from Ganoderma lucidum as a potential drugs in Alzheimer's disease}

A number of indicators of active inflammation processes have been found in the brains of patients with Alzheimer's disease (20). Cerebral ( $\beta$-amyloid protein deposition, characteristic of Alzheimer's disease, is associated with a predominantly local acute phase response that kindles release of various inflammatory and immune system mediators. The molecular events are accompanied by a profound cellular response which is largely controlled by microglia. Current evidence suggests that microglia are primarily responsible for inducing further neuronal damage by generating reactive oxygen species and proteolytic enzymes (8). Lesions in chronic neurodegenerative diseases, as Alzheimer's disease, are associated with a variety of proteins known to be involved in inflammatory processes (14). Researches in the United States and Canada have found that long-time ingestion of nonsteroidal anti-inflammatory drugs can slow the progress of the Alzheimer's disease and that use of nonsteroidal anti-inflammatory drugs is associated with reduced risk of Alzheimer's disease (2,3,15,19). In a report by Corrada et al. (7) reported on finding on 1417 men and 648 women from Baltimore Longitudinal Study of Aging which is 37 year study of normal aging. The results suggests that the use of nonsteroidal anti-inflammatory drugs is associated with decreased incidence of Alzheimer's disease. This research heightens the importance of the ancient reports where G. lucidum was praised for its effect of increasing memory and preventing forgetfulness in old age reported in Shen Nong Ben Cao Jing as early as in 456-536 AD (16).

The mechanism of action of inflammatory drugs is based on their capability to inhibit the biosynthesis of prostaglandins. Antiinflammatory drugs are presumed to act by inhibiting cyclooxygenase (COX), a key enzyme in the metabolism of membrane-derived arachidonic acid into prostaglandins (26). In past few years, two distinct isoforms of COX have been characterized, a constitutive isoform COX-1, and a mitogen-inducible isoform, COX-2. The COX2 represents a possible target of nonsteroid anti-inflammatory drugs action in neurodegenerative mechanisms (18). It seems that the future treatment strategies of Alzheimer's disease treatment will likely include a combination of acetylcholinesterase inhibitors and disease-modifying agents like nonsteroide anti-inflammatory drugs (21) and triterpenoids from $\mathrm{G}$. lucidum may be in the future so anti-inflammatory drugs with a good benefit.

\section{Conclusions}

A family of triterpenoids from the Ganoderma lucidum, mysterious mushroom of Orient, to be potent anti-inflammatory agents. This ancient drug was encouraged for its effect of increasing memory and preventing forgetfulness 
in old age and it is very probably that this effect could be employ in modern medicine in the treatment of Alzheimer's disease.

\section{References}

1. Asai R. Miracle Cure: Organic Germanium. New York: Japan Publications/ Kodansha International via Harper and Row, 1980.

2. Beard CM, Waring SC, O'Brien PC, Kurland LT, Kokmen E. Nonsteroidal antiinflammatory drug use and Alzheimer's disease: a case-control study in Rochester, Minnesota, 1980 through 1984. Mayo Clin Proc 1998;73:951-5.

3. Braitner JC, Gau BA, Welsh KA et al. Inverse association of anti-inflammatory treatments and Alzheimer's disease: initial results of a co-twin control study. Neurology 1994;44:227-32.

4. Buchannan PK, Hseu RS, Moncalvo JM (Eds.). Ganoderma: Systematics, Phytopathology and Pharmacology. Proceedings of Contributed Symposia 59 B, 5th International Mycological Congress, Vancouver, August 14-21, 1994.

5. Chang HM, But BPH. Pharmacology and Applications of Chinese Materia Medica. Vol 1 and 2, World Scientific, Singapore 1986 and 1987.

6. Chang ST, Buswell JA, Chiu SW (Eds.).Mushroom Biology and Mushroom Products. Chang ST, Buswell JA, Chiu SW (Eds.). Hong Kong: The Chinese University Press, 1993:267.

7. Corrada M, Stewart W, Kawas C. Nonsteroidal anti-inflammatory drugs and the risk of Alzheimer's disease. Neurology 1996;46:A433.

8. Kalaria RN, Cohen DL, Premkumar DR. Cellular aspects of the inflammatory response in Alzheimer's disease. Neurodegeneration 1996:5:497-503.

9. Kino K, Sone T, Watanabe $\mathrm{J}$ et al. Immunomodulator, LZ-8, prevents antibody production in mice. Int J Immunopharmacol 1991;13:1109-15.

10. Lin JM, Lin CC, Chiu HF, Yang JJ, Lee SG. Evaluation of the anti-inflammatory and liver- protective effects of Anoectochilus formosanus, Ganoderma lucidum and Gynostemma pentaphyllum in rats. Am J Chin Med 1993;21:59-69.

11. Lin LJ, Shiao MS. Separation of oxygenated triterpenoids from Ganoderma lucidum by high-performance liquid chromatography. J Chromatogr 1987;410:195200.

12. Lin WS, Chan WC, Hew CS. Superoxide and traditional Chinese medicines. J Ethnopharmacol 1995;45:165-71.

13. Matsumo K. The Mysterious Reishi Mushroom. Santa Barbara: Woodbridge Press Publ. Comp., 1979.

14. McGeer EG, McGeer PL. The importance of inflammatory mechanisms in Alzheimer disease. Exp Gerontol 1998;33:371-8.
15. McGeer P, Rogers J. Anti-inflammatory agents as a therapeutic approach to Alzheimer's disease. Neurology 1992;42:447-9.

16. Mizuno T. Oriental medicinal tradition of Ganoderma lucidum (Reishi) in China. In: Mizuno T, Kim B-K (Eds). Ganoderma lucidum. Seoul, Korea: Il-Yang Pharm Co. Ltd., 1996:101-6.

17. Myazaki T, Nishijima M. Studies on fungal polysaccharides. XXXVII. Structu examination of a water-soluble, antitumor polysaccharide of Ganoderma lucidum. Chem Pharm Bull 1981;29:3611-6.

18. Pasinetti GM, Aisen PS. Cyclooxygenase-2 expression is increased in frontal cortex of Alzheimer's disease brain. Neuroscience 1998;87:319-24.

19. Rich JB, Rasmusson DX, Folstein MF, Carson KA, Kawas C, Brandt J. Nonsteroidal anti-inflammatory drugs in Alzheimer's disease. Neurology 1995;45:51-5.

20. Rogers J. Inflammation as a pathogenic mechanism in Alzheimer's disease Arzneimittel-Forsch 1995;45:439-42.

21. Shadlen MF, Larson EB. What's new in Alzheimer's disease treatment? Reason for optimism about future pharmacologic options. Postgrad Med 1999;105:109. 18

22. Stavinoha W, Satsangi N, Weintraub S. Study of the antiinflammatory efficacy of Ganoderma lucidum. In: Kim B-K, Kim YS (Eds.). Recent Advances in Ganoderm lucidum Research. Seoul: The Pharmaceutical Society of Korea, 1995; 3-7.

23. Streeper RT, Satsangi N, Stavinoha WB, Weintraub ST. Anti-inflammatory components of mushroom extract on SUPELCOSIL ABZ+Plus HPLC Columns. The Reporter 1995; 14(5): 1-3.

24. Tasaka K, Akagi M, Miyoshi K, Mio M, Makino T. Anti-allergic constituents in the culture medium of Ganoderma lucidum. (I). Inhibitory effect of oleic acid on histamine release. Agents Actions 1988;23:153-6.

25. Tasaka K, Mio M, Izushi K, Akagi M, Makino T. Anti-allergic constituents in the culture medium of Ganoderma lucidum. (II). The inhibitory effect of cyclooctasulfur on histamine release. Agents Actions 1988;23:157-60.

26. Vane JR, Botting RM. Mechanism of action of antiinflammatory drugs. Int J Tissue React 1998;20:3-15.

Doc. RNDr. Jiři Patočka, DrSc.,

Department of Toxicology,

Purkyně Military Medical Academy, 50001 Hradec Králové,

Czech Republic. e-mail: patocka@pmfhk.cz 